\title{
Impact of Holocene climate change on the prehistoric cultures of Zhejiang region, East China
}

\author{
WU Li ${ }^{1,2},{ }^{*}$ ZHU Cheng ${ }^{2}$, ZHENG Chaogui ${ }^{3}$, MA Chunmei ${ }^{2}$, WANG Xinhao ${ }^{4}$, \\ LI Feng ${ }^{2}$, LI Bing ${ }^{2}$, LI Kaifeng ${ }^{2}$ \\ 1. College of Territorial Resources and Tourism, Anhui Normal University, Wuhu 241003, Anhui, China; \\ 2. School of Geographic and Oceanographic Sciences, Nanjing University, Nanjing 210023, China; \\ 3. Geographic Information and Tourism College, Chuzhou University, Chuzhou 239000, Anhui, China; \\ 4. School of Earth Sciences and Engineering, Hohai University, Nanjing 210098, China
}

\begin{abstract}
The temporal-spatial distribution features of prehistoric cultures since the Holocene in Zhejiang region were comparatively analyzed based on GIS spatial analysis. Results show that the prehistoric cultures expanded gradually in this region before 4000 cal. a BP. The notable expansions occurred twice, one in the Majiabang-Hemudu cultural period, the other in the Liangzhu cultural period. Meanwhile, the prehistoric cultures were disseminated from west to east coast along river valleys. After 4000 cal. a BP, as represented by the Maqiao Culture, the distributed area of each prehistoric culture contracted. This is obviously due to the termination of spreading trends to east coast, which was simultaneously accompanied by two different modes of production and economic transitions in the north and south Zhejiang region respectively. The distribution of prehistoric cultures was closely related with Holocene sea-level fluctuations, especially on the banks of Hangzhou Bay, where the distribution changes of prehistoric cultural sites were greatly affected by sea-level changes, with the closest relationships between them. After 7000 cal. a BP, the process of lowered sea-level and regression-epeirogenesis provided wider terrestrial living spaces for prehistoric inhabitants. Based on the comparative analyses of the changes of prehistoric cultures and the environmental evolution information recorded in the Qianmutian subalpine peat of Mt. Tianmu and muddy area on the inner shelf of the East China Sea, it is indicated that the changes of prehistoric cultures were synchronized with environmental changes in Zhejiang region. Before 4000 cal. a BP, the eastward expansion of prehistoric cultures in Zhejiang occurred under the background of the Holocene Optimum, and was the expansion and extension under the joint influences of agricultural civilization and maritime civilization. However, after 4000 cal. a BP, the geographical contraction of prehistoric cultures in Zhejiang occurred under the back-
\end{abstract}

Received: 2013-09-23 Accepted: 2013-10-29

Foundation: National Natural Science Foundation of China, No.41171163; No.41271516; Major Program of National Social Science Foundation of China, No.11\&ZD183; National Key Technology R\&D Program of China, No.2013BAK08B02; Open Foundation of State Key Laboratory of Lake Science and Environment, Nanjing Institute of Geography \& Limnology, CAS, No.2012SKL003; Open Foundation of State Key Laboratory of Loess and Quaternary Geology, Institute of Earth Environment, CAS, No.SKLLQG1206; Doctoral Scientific Research Foundation of Anhui Normal University, No.161-070143

Author: Wu Li (1985-), PhD and Lecturer, specialized in geomorphology and Quaternary environmental archaeology. E-mail: jedi-wuli@163.com

*Corresponding author: Zhu Cheng (1954-), PhD and Professor, E-mail: zhuchengnj@126.com 
ground of dry-cold climate trend and deterioration of coastal marine environment. It is evidenced from the above fact that the development, expansion and contraction of prehistoric cultures are positively correlated to environmental change. The change of the climatic environment is just the underlying reason for these changes and transitions of production modes and economic forms. Therefore, the climatic environment is the dominant factor of prehistoric culture vicissitudes in Zhejiang region, which has exerted great influence on distribution, dissemination, expansion and transmutation of the culture.

Keywords: Zhejiang; climate change; prehistoric culture; Holocene

\section{Introduction}

Zhejiang region, which is located just south of the Yangtze River Delta, is an eastern coastal province of China. Zhejiang borders Jiangsu and Shanghai to the north, Anhui and Jiangxi to the west, and Fujian to the south. To the east is the East China Sea, beyond which lie the Ryukyu Islands of Japan. It ranges between $27^{\circ} 12^{\prime}-31^{\circ} 31^{\prime} \mathrm{N}$ and $118^{\circ}-123^{\circ} \mathrm{E}$ with an area of $101,800 \mathrm{~km}^{2}$. Zhejiang consists mostly of hills, which account for $70 \%$ of its total area. Valleys and plains are found along the coastline and rivers. Also there are over 3000 islands along the rugged coastline of Zhejiang. Zhejiang has a humid subtropical climate with four distinct seasons. Average annual temperature is around $15-19^{\circ} \mathrm{C}$, and annual precipitation is about 1000-1900 $\mathrm{mm}$. Therefore, it is part of the sea-land transitional zone of China's eastern monsoon region. Its natural environment has strong transitional and unstable features, and has significant sensitivity to climate change.

As the important distribution areas of prehistoric culture in China, from the Shangshan Culture and the Xiaohuangshan Culture of the early Neolithic age to the Spring and Autumn and the Warring States periods, Zhejiang region is one of the most important places of prehistoric cultural activities in eastern China (Ye et al., 2010). Due to the sensitivity of natural environment of the sea-land transitional zone to the response of climate change, as well as long-term accumulation of rich ancient cultural relics, Zhejiang region has become an ideal zone for studying the impact of past global environmental change on human society (Fang et al., 2004; Wu and Liu, 2004). Currently, a number of scholars have carried out preliminary research into environmental evolution and ancient cultural transition (Wu, 1983; Jiang et al., 1999; Ye et al., 2010; Wu et al., 2012a), mainly in the aspects of the archaeological stratigraphy study of typical sites and natural environment evolution (Yan and Huang, 1987; Gu et al., 2005; Liu et al., 2007; Zong et al., 2007; Innes et al., 2009; Shu et al., 2010; Shi et al., 2011). However, research on the temporal-spatial distribution features of Holocene prehistoric cultural sites in Zhejiang region, and integrated comparisons dealing with environmental archaeology studies combined with high resolution natural environment evolution sequences have not been taken seriously. Only if we take into account prehistoric cultures and environmental system as a whole, can we show the distribution and evolution of cultures with their climate change relationships comprehensively.

\section{Evolution of prehistoric cultures in Zhejiang region}

There were many Chinese Neolithic cultural sites enriched in Zhejiang region. These prehistoric cultures played an important role in the origin and development of Chinese civiliza- 
tion, including the Shangshan Culture, Kuahuqiao Culture, Hemudu Culture, Majiabang Culture, Songze Culture, Liangzhu Culture and Maqiao Culture. The Shangshan Culture was the earliest Neolithic cultural type found in Zhejiang until now. Archaeologists have excavated cultivated rice remains; the $\mathrm{AMS}^{14} \mathrm{C}$ and $\mathrm{OSL}$ calibrated age proved that this culture existed between 11,400-8600 cal. a BP (Mao et al., 2008). The Kuahuqiao Culture was an early-middle Neolithic culture, and mainly distributed at confluence of downstream of Puyang River with Qiantang and Fuchun rivers. A large number of painted potteries originating from this culture have been unearthed, and its age was about 8200-7500 cal. a BP (Zong et al., 2007; Mo et al., 2010). Compared with the inland Shangshan Culture, the Kuahuqiao Culture was developed from the lower coastal plains, having certain characteristics of marine culture. After the Kuahuqiao Culture, the Hemudu Culture was a middle Neolithic culture with its wetland agriculture as the main means of livelihood, belonging to the matriarchal commune period (Mo et al., 2010). This culture was mainly distributed in the Ningshao Plain on the south bank of Hangzhou Bay and the Zhoushan Islands, and its age was 7000-5300 cal. a BP. Meanwhile, the Majiabang Culture (7000-5900 cal. a BP) and Songze Culture (5900-5300 cal. a BP) successively developed and occupied the Hangjiahu Plain on the north side of Hangzhou Bay. They were all the middle-late Neolithic cultures originated in the Taihu Lake Basin, and were well-known for polished stone tools and refined jade artefacts. The Liangzhu Culture was the last Neolithic culture in Zhejiang (5300-4000 cal. a BP), belonging to the disintegration period of primitive society. This culture had national prototypes, and was distributed in most parts of Zhejiang. It was famous for its superior and advanced processing technology of jade artefacts. The Maqiao Culture (3900-3300 cal. a BP) was a kind of Chalcolithic culture after the Liangzhu Culture in Zhejiang, and was also the last prehistoric culture, which was equal to the Xia and Shang dynasties of Central Plains in China (SACH, 2009). It is observed that these prehistoric cultures have good continuity, and also have certain interval relations geographically. Therefore, this makes it possible to study the temporal-spatial distribution changes of prehistoric cultural sites in Zhejiang region.

On the other hand, prehistoric cultures of Zhejiang region have a close relationship with prehistoric cultures of the adjacent Taihu Lake Basin (SACH, 2009; Wu et al., 2014), and were also related with Fujian's prehistoric cultures. They all belonged to the southeast coastal area of China. At present, prehistoric cultures from the Taihu Lake Basin and Fujian region all have specialized researches (Lin, 2003; Zhu et al., 2003). There should be a special meaning for carrying out research of Zhejiang's prehistoric cultures, which existed in the transitional zone between the two aforementioned regions.

\section{Materials and methods}

Essential materials of cultural site distribution maps include three spatial data sources: a SRTM Digital Elevation Model (DEM) with a resolution of $90 \mathrm{~m} \times 90 \mathrm{~m}$, as well as topographic and drainage maps. The dataset is provided by the International Scientific Data Service Platform (http://datamirro.csdb.cn), Computer Network Information Center, Chinese Academy of Sciences. The positional data of archaeological sites is collected from An Atlas of Chinese Cultural Relics in Zhejiang Province (SACH, 2009). According to the related archaeological data and materials, all the prehistoric cultural sites in Zhejiang are plotted on 
a relief map, i.e., the Chinese vector electronic map, using MapInfo Professional 7.8 SCP software to create the point layer and identify the number, names, archaeological cultures and positions of sites. The electronic Chinese vector map is then transformed into the Arc GIS shp format to obtain layers of cities, rivers, reservoirs, lakes and the basic point layer, thus establishing a workspace, and the DEM data was then added. Arc GIS data extraction tools were utilised to obtain the longitude, latitude and elevation information of cultural sites and add the property charts. Therefore, all the layers in the given workspace were edited, such as adjusting lines and symbols, setting colours and adding map elements (legend, scale and compass) to create the temporal-spatial distribution map of prehistoric cultural sites in Zhejiang (Figures 1-4). The spatial distribution patterns were analyzed taking dotted cultural sites as unit in the study.

\section{Temporal-spatial distribution of prehistoric cultures in Zhejiang region}

Prehistoric cultural sites of Zhejiang region have dotted distribution characteristics, and are mainly distributed in flat and fertile land of Hangjiahu Plain and Ningshao Plain. They are secondly distributed at the coastal hilly regions of eastern Zhejiang and the first or second river terraces of mountainous area in southwest Zhejiang.

At present, the site number of Shangshan cultural sites was seldom found in Zhejiang region. The Xiaohuangshan cultural site also belongs to the same archaeological period. So there were totally two cultural sites in this period, only distributed in the upper reaches of the Puyang River and Cao'e River valley basin of Shengzhou, adjacent to the Ningshao Plain (Figure 1). The site number of Kuahuqiao Culture was also very low, with only one site. Compared with the former stage, its settlement site gradually transferred to the plains in the lower reaches of the Puyang River (Figure 1). The geomorphic type of Hemudu cultural sites' distribution was basically the same as the Kuahuqiao Culture. The Hemudu cultural sites were widely distributed on both sides of the Yaojiang River valley plains (less than 100 $\mathrm{m}$ above m.s.1.) to the east of Ningshao Plain. The maximum distribution range of Hemudu Culture borders the Zhoushan Islands to the east, the upstream valley basin of Puyang River to the west, the Hangzhou Bay to the north, and coastal hilly regions of southeast Zhejiang to the south. There were more than 30 cultural sites found from the Hemudu cultural period. These sites are densely distributed on both sides of the eastern Yaojiang River valley. For example, there were 24 Hemudu cultural sites found in Yuyao, and four sites found in Ningbo, which accounted for $72.7 \%$ and $12.1 \%$ of the total found Hemudu cultural sites respectively, indicating a typical concentration area. The site number to the east and south was the second, and to the west the site numbers decreased rapidly, only one site found in the west Ningshao Plain (Figure 2).

At the same time as the rise of the Hemudu Culture, the Majiabang Culture was developing in the north of the Hangzhou Bay. The site distribution law of the Majiabang Culture differed greatly from the Hemudu Culture. The distribution area of the Majiabang Culture was larger. Majiabang cultural sites not only extended northwestward to the piedmont area of Mt. Tianmu in the upper reaches of the East and West Tiaoxi River, but also have been found along both sides of the middle and lower reaches of the Puyang River to the south of Hangzhou Bay. However, the site distribution density of the Majiabang Culture is obviously 


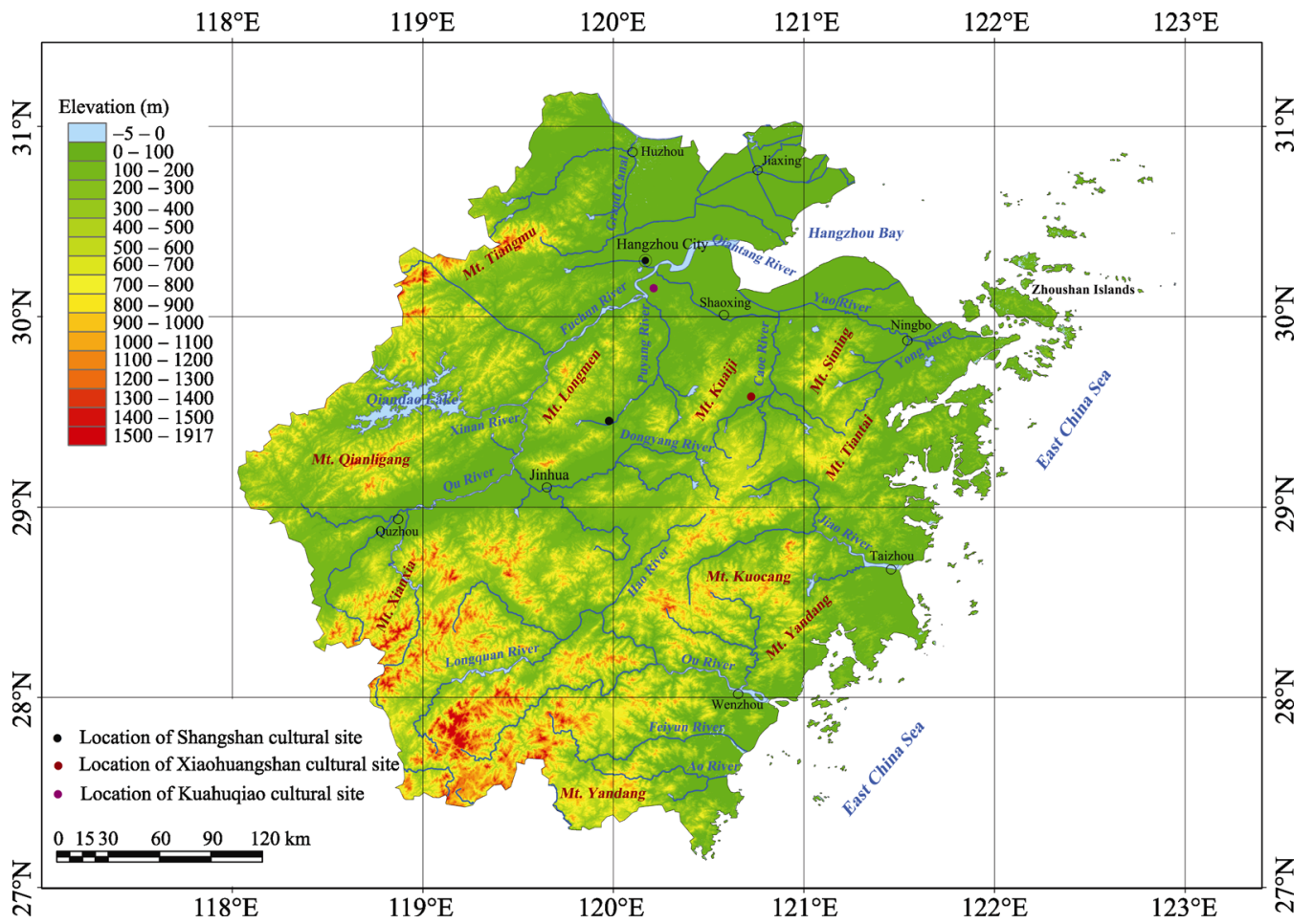

Figure 1 Archaeological sites of Zhejiang region in the early Neolithic period (11400-7500 cal. a BP)

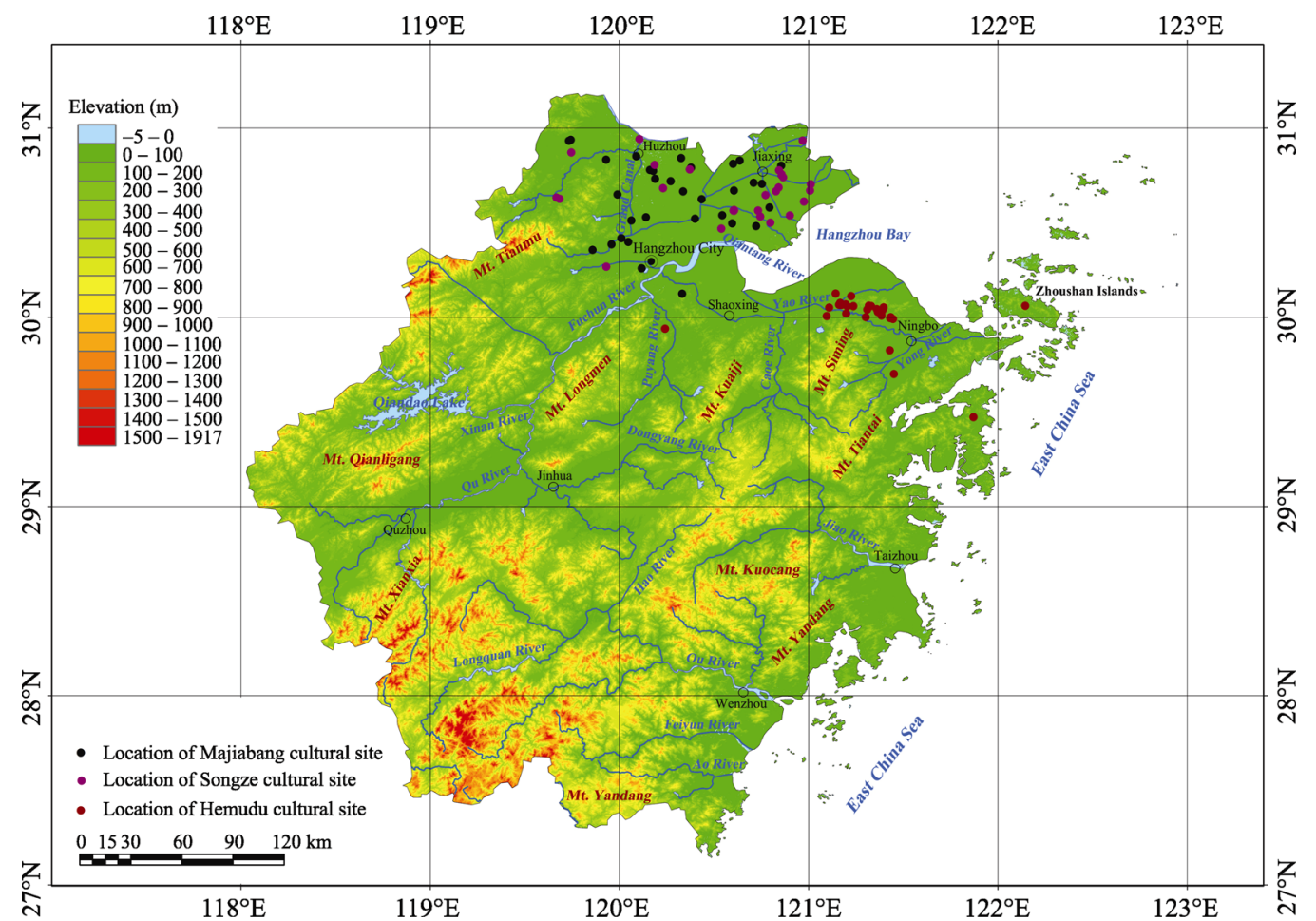

Figure 2 Archaeological sites of Zhejiang region in the middle Neolithic period (7000-5300 cal. a BP) 


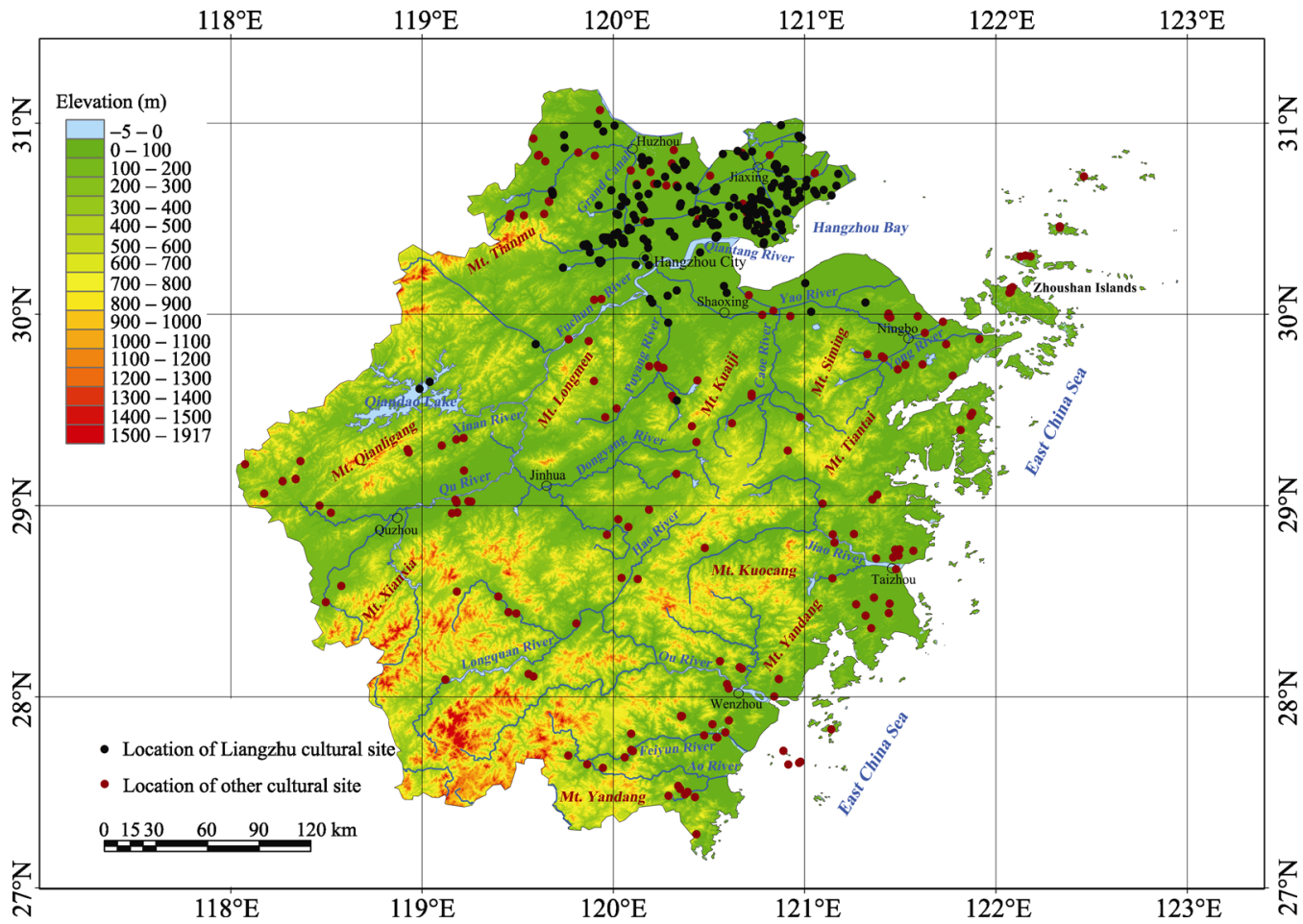

Figure 3 Archaeological sites of Zhejiang region in the late Neolithic period (5300-4000 cal. a BP)

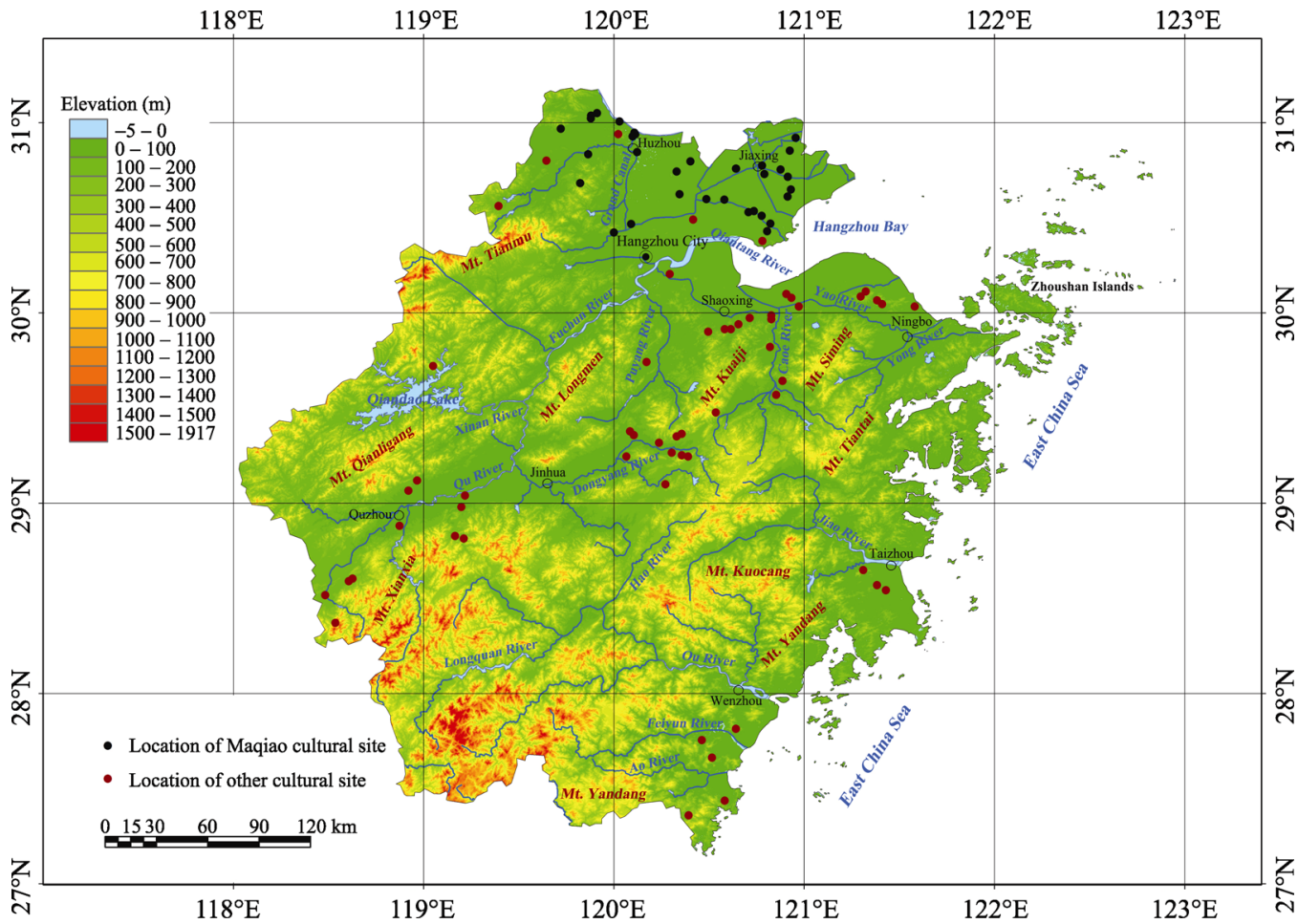

Figure 4 Archaeological sites of Zhejiang region in the Xia and Shang dynasties (3900-3300 cal. a BP) 
lower than the Hemudu Culture. The density of sites is 5.24 sites $/ 100 \mathrm{~km}^{2}$ in the concentration area of the Hemudu Culture, while the densities of sites in two concentration areas (i.e. the piedmont area of Mt. Tianmu in the west and the Hangjiahu Plain in the east) of the Majiabang Culture are 0.63 sites $/ 100 \mathrm{~km}^{2}$ and 0.57 sites $/ 100 \mathrm{~km}^{2}$ respectively. It is worth noting that the archaeological remains of the Tashan site located in Xiangshan County, east Zhejiang, reflect a unique phenomenon of cultural encounters but incomplete compatibility between the Hemudu Culture and the Majiabang Culture, forming a new Tashan cultural type (Jiang, 1999). This site, up to now, is known as the common southern distribution boundary of the above two cultures.

Inherited from the Majiabang Culture's development, the distribution area of the Songze Culture was basically the same as the Majiabang Culture. But the difference was that the Songze cultural sites showed the distribution feature of being dense in the east and sparse in the west, and their distribution area was reduced (Figure 2). During this period, the site numbers of the piedmont area of Mt. Tianmu were reduced greatly, especially along the East Tiaoxi River valley. However, the eastward expansion trend of sites was obvious, and the distribution of sites was closer to the coastal zone along the north shore of Hangzhou Bay. From Figure 2, we also can find that there were no Songze cultural sites distributed to the south of Hangzhou Bay, and the Hemudu cultural sites were still distributed densely in the valleys and plains in the eastern Ningshao Plain. Because the site numbers reduced during the Songze cultural period, and their distribution expanded eastward to the east of the Jiaxing-Haiyan line, the distribution density of Songze cultural sites was also reduced obviously relative to the Majiabang Culture. But in the eastern Hangjiahu Plain, the density of sites was significantly larger $\left(1.54\right.$ sites $\left./ 100 \mathrm{~km}^{2}\right)$ in the concentration area of Songze Culture, indicating that the centralization and development degree of settlements reached a higher level at this time.

The Liangzhu Culture was the most widely distributed cultural type in Zhejiang, and the number of found sites was also the highest (Figure 3). The Liangzhu Culture not only covered almost all distribution areas of the former several cultures, but also developed and expanded substantially, increasing to 275 sites. These Liangzhu cultural sites distributed west to the Tonglu and Chun'an, developed northward to the northern rim of the West Tiaoxi River valley on the west bank of the Taihu Lake, expanded southward to Zhuji and Yiwu City in the upper and middle reaches of the Puyang River, and also extended eastward to the Yaojiang River valley. Seen from this distribution range, there were widespread areas, including the south bank of the Taihu Lake, the north of Mt. Qianligang-Mt. Kuaiji-Mt. Siming line, and the east of Mt. Tianmu extending to the coastal zone, had a distribution of Liangzhu cultural sites. However, their distributed centres concentrated in the eastern Hangjiahu Plain and the upper-middle reaches of the East Tiaoxi River, and diverged all around. For example, there are more than 40 sites distributed in Haining City. During this period, the centralization and development degree of prehistoric cultural settlements reached the highest level. The density of sites is 3.55 sites $/ 100 \mathrm{~km}^{2}$ in the concentration area to the north of Hangzhou Bay. Furthermore, there were many other cultural sites with uncertain cultural attributes appearing within the scope of vast areas in Zhejiang during this period, and the number of these sites reaches nearly 200 . The representative sites were the Coastal Island cultural type distributed at the Zhoushan Islands and Nanji Islands (SACH, 2009), and the 
Haochuan cultural type distributed along the Oujiang River in south Zhejiang (Shu, 2010).

From the end of Liangzhu cultural period to the Xia and Shang dynasties of China, the major archaeological culture in Zhejiang was the Maqiao Culture. Compared with the Liangzhu Culture, the distribution range of Maqiao Culture was much narrower, but the sites were still mainly distributed in the eastern part of the Hangjiahu Plain, and secondly in the southwest coastal area of the Taihu Lake (Figure 4). Tombs from Maqiao Culture have not yet been found in Zhejiang region (SACH, 2009). There were only 34 Maqiao cultural sites found throughout the region, and the Maqiao cultural layer generally covered the Liangzhu cultural strata directly or indirectly. Relics of Maqiao Culture were not rich, and there was a large connotational difference between Liangzhu Culture and Maqiao Culture. However, the southernmost distribution of Maqiao Culture has reached to the south of Wenzhou in the upper reaches of the Feiyun River, especially the Shizigang site of Siqian County and the Niutougang archaeological site of Baizhang County. Both are regarded as two typical representatives (SACH, 2009). Ancestors' traces of typical ancient Yue Culture were also found first in Zhejiang region during this period. In addition to the archaeological sites throughout the province, burial forms from Yue Culture were present in the mound tombs in the northern and central Zhejiang region; while in Wenzhou and its southern part, it was characterized by dolmen tombs. This indicated that differentiation had occurred among the ancient Yue ethnic groups and their artefacts' features were outstandingly embodied as the widespread appearance of press marked pottery and protoporcelain (Song, 1999).

Thus it can be seen that, from the Shangshan Culture to the Maqiao Culture for thousands of years of development (i.e. 11400-3300 cal. a BP), the living space of original inhabitants expanded on the whole, only declining significantly in the Maqiao cultural period. The cultural development level also significantly declined during this period. There were two notable territory expansions of prehistoric cultures. The first expansion occurred in the Majiabang-Hemudu cultural period. The distribution of the Kuahuqiao Culture was very limited. But after the $7000 \mathrm{cal}$. a BP, the distribution range of prehistoric cultures widened sharply, and continued its consistent scope during the Songze-Hemudu cultural period, keeping the situation stable. The other expansion occurred in the Liangzhu cultural period. The distribution range of this period greatly expanded, and got rid of the pattern developed along the piedmont river valley and lacustrine plain. There was a new feature that the sites spread both to the higher mountains and hills and the lower coastal plains. If we take various uncertain cultural sites (such as the Haochuan culture, etc.) as an important organic component of the Zhejiang prehistoric cultures during the Liangzhu cultural period, the distribution of prehistoric ancestors was wider. Meanwhile, the concentrational areas of prehistoric cultures in Zhejiang disseminated continuously to the east. In areas to the north of Hangzhou Bay, the Majiabang culture only distributed at the piedmont region of Mt. Tianmu in the west and the Hangjiahu Plain in the east, and then the cultural sites extended to the East Tiaoxi River valley and the coastal plains to the east of Jiaxing-Haining. In areas to the south of Hangzhou Bay, the Shangshan Culture only distributed at intermontane basins in the upper reaches of the Puyang River, and then the cultural sites migrated to the lower reaches and plains of the Puyang River during the Kuahuqiao cultural period; at last, the cultural sites 
migrated eastward to the eastern part of the Ningshao Plain and the southeast coastal areas as well as offshore islands along the Yaojiang River valley during the Hemudu cultural period. Therefore, the prehistoric cultures were generally disseminated from the west to the east coast along the main drainage river valleys of Zhejiang region.

\section{Prehistoric cultural vicissitude and environmental change of Zhejiang}

The spatial distribution of prehistoric cultures has obvious regionality in Zhejiang. Under the influence of topographic factors, sea-level change and climatic environmental change are also two important factors that cannot be ignored. In fact, sea-level change was also usually driven by the changes in the climatic environment.

\subsection{Relationship between prehistoric cultural vicissitude and sea-level change}

Because Zhejiang belongs to a coastal province, its wide coastal lowland plain areas were significantly affected by Holocene sea-level fluctuations. In particular, the distribution of prehistoric cultural sites on both sides of Hangzhou Bay was strongly influenced by sea-level change. In areas to the north of Hangzhou Bay, research on Holocene sediment and transgression of the Hangjiahu Plain show that (Yan and Shao, 1989; Zhu et al., 2003), the largest transgression since the Holocene occurred prior to 7000 cal. a BP. After 7000 cal. a $\mathrm{BP}$, the plain has experienced an obvious process of regression-epeirogenesis into the southeast. The area to the east and south of the Jiaxing-Majiabang-Chongfu-Changanzhen line was a neritic environment at that time, while the area to the west of the line and to the Luojiajiao site was also in a coastal marsh environment (Yan and Hong, 1987), being unsuitable for human settlement. Therefore, there were no prehistoric cultural sites found earlier than the Majiabang cultural period in the Hangjiahu Plain until now. By around 6000 cal. a BP, the coastline of eastern plain had advanced rapidly to the west of the Haiyan-Zhapu line, and the southern coastline had also advanced to the south of Yuhang (Yan and Huang, 1987). During this period, the Majiabang cultural sites were widely distributed in the Hangjiahu Plain, but the outboard area of paleocoastline, which was located to the east of the Haiyan-Zhapu line and to the south of Yuhang, did not have any distribution of Majiabang cultural sites at all. After 5000 cal. a BP, the Hangjiahu Plain had all become land locked, as it is today, and the area around Hangzhou City also ended the history of estuary depositional environments in the Liangzhu cultural period (Cai, 2001), as evidenced by the dense distribution of Liangzhu cultural sites in the coastal lowland of the eastern plain and the Hangzhou surrounding areas during this period. But in the Maqiao cultural period, cultural sites were greatly reduced in the coastal lowland of eastern Jiaxing and northeast Hangzhou. This might be related to a sea-level rise event between 4000-3000 cal. a BP (Chen et al., 2008).

In areas to the south of Hangzhou Bay, there was primarily a process of regression-epeirogenesis in the Ningshao Plain since the Holocene (Feng and Wang, 1986; Zhu et al., 2003). Correspondingly, the spatial distribution of prehistoric cultural sites gradually concentrated from the valley basin and hilly area of central Zhejiang during the Shangshan cultural period to the estuary and coastal plain area during the Kuahuqiao and Hemudu cultural periods. From the chronology, sedimentary stratigraphy and micropaleontology analysis of the Kuahuqiao site $\left(30^{\circ} 08^{\prime} 42^{\prime \prime} \mathrm{N}, 120^{\circ} 13^{\prime} 02^{\prime \prime} \mathrm{E}\right.$, and $4.0 \mathrm{~m}$ a.s.l.) and the Xianghu sec- 
tion $\left(30^{\circ} 08^{\prime} 36^{\prime \prime} \mathrm{N}, 120^{\circ} 12^{\prime} 58^{\prime \prime} \mathrm{E}\right.$, and $5.0 \mathrm{~m}$ a.s.1.) in the south bank of the Qiantang River of the west Ningshao Plain, as well as the Hemudu site $\left(29^{\circ} 58^{\prime} \mathrm{N}, 121^{\circ} 22^{\prime} \mathrm{E}, 2.4 \mathrm{~m}\right.$ a.s.1., and 75 $\mathrm{km}$ away from the Kuahuqiao site) in the east Ningshao Plain (Figure 5), we can see that neritic facies can be compared between the sediments below the Hemudu cultural layer and the accumulations above the Kuahuqiao cultural layer in the middle of the Xianghu section and the Kuahuqiao site. This means that the neritic sediments of the aforementioned three sites were formed as the products of contemporary transgressive processes, and also that the largest transgression of the Ningshao Plain since the Holocene should have happened between 7500-7000 cal. a BP. The first high sea-level since the Holocene might have occurred

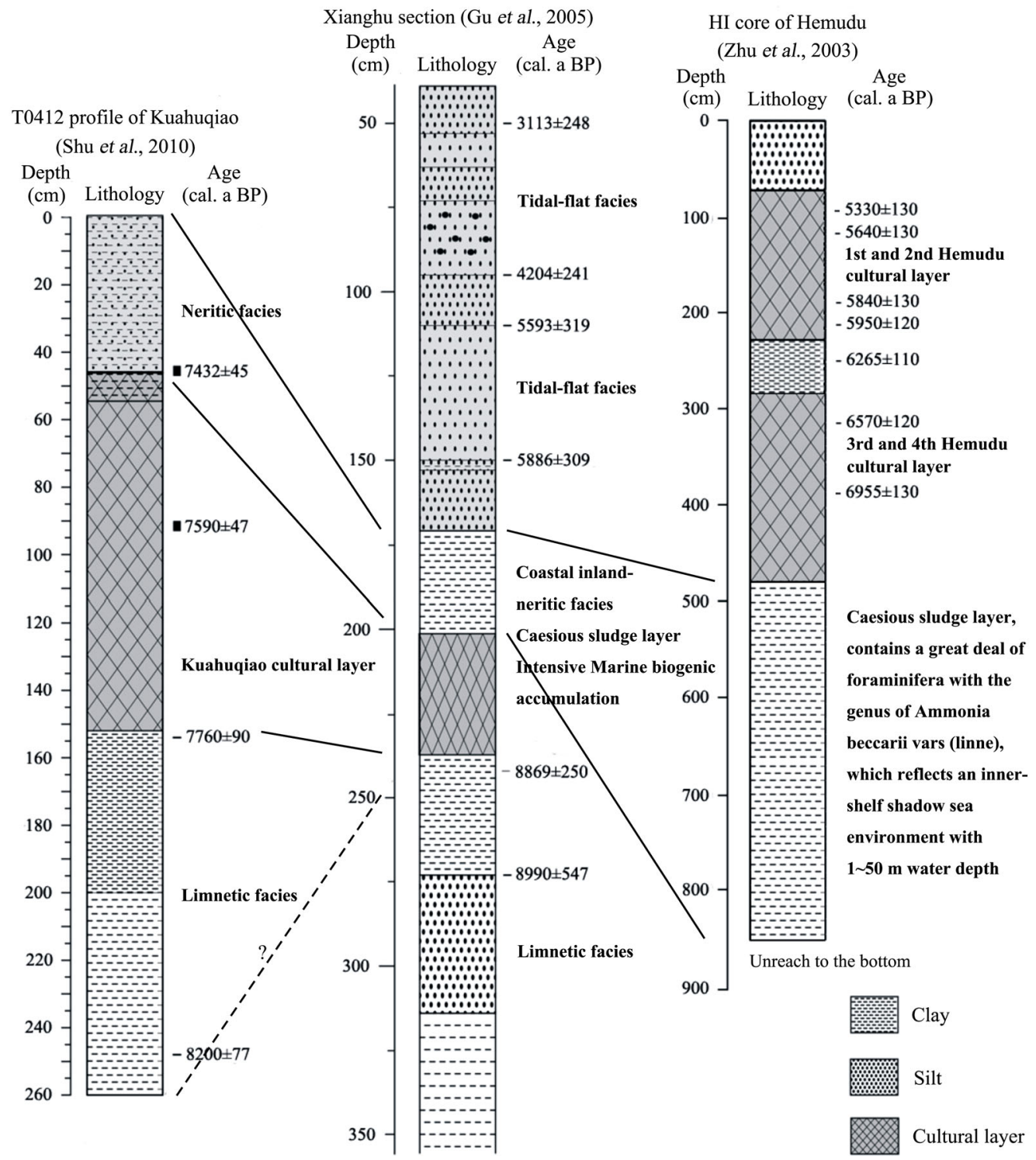

Figure 5 Holocene stratigraphic correlation among the three profiles (Xianghu section, T0412 profile of Kuahuqiao cultural site and HI core of Hemudu cultural site) associated with their calibrated radiocarbon ages in the Ningshao Plain 
around 7500 cal. a BP in this area, and was close to or slightly higher than the modern sea-level at that time (Zhu et al., 2003; Gu et al., 2005; Zong et al., 2007; Shi et al., 2008). The geographic location of the Kuahuqiao-Xiasun site, and its marine bed above the cultural relics with the chronological evidence confirmed the occurrence of high sea-levels and a transgressive event in the middle-late stage of Kuahuqiao Culture (Shu et al., 2010), catching a glimpse of traces from the Qiantang tidal bore between 7500-7000 cal. a BP (Shi et al., 2008). This might be the important reason that cultural sites between the end of Kuahuqiao cultural period and the beginning of Hemudu cultural period about 500 years later have not been found in the Ningshao Plain. The Hemudu cultural sites appeared in the mid-east region of Ningshao Plain after 7000 cal. a BP, when the phase of low sea-level just occurred (Li et al., 2010), which was consistent with the sea-level changes in areas to the south of the Hangzhou Bay. From the comparison and formation analysis of "Event layers" (i.e. the cultural intermittent layer formed by fluviation) included in many typical archaeological strata in the Ningshao Plain (Shi et al., 2008), it can be seen that many archaeological strata of cultural sites have "Event layers" during 6000-5500 cal. a BP and 5000-4500 cal. a BP in this area. This may be associated with the rise of groundwater level or surface water expansion caused by some short scale sea-level fluctuations. The temporary migration phenomena of ancient humans may have occurred during the formative period of "Event layers" (Sun, 2002). This is another phenomenon that is worthy of attention. The cultural layer with the depth of 100-500 cm of HI core in the Hemudu site showed that the site area has formed land with lower sea-level between $6955 \pm 130$ cal. a BP and $5330 \pm 130$ cal. a BP. However, the Xianghu section of Xiaoshan displayed the depositional feature of tidal-flat facies during this period. This shows that even in the phase of regression, there still existed certain differences of sedimentary environment between the east and the west of the Ningshao Plain, reflecting the complexity of regional coastline changes.

\subsection{Relationship between prehistoric cultural vicissitude and climate change}

Zhejiang is located in the coastal zone belonging to the eastern part of the East Asian monsoon region, and is one of the areas most sensitive to climate change in the world (Ma et al., 2009; Liu et al., 2010). Global climate change is often manifested in these sensitive areas first. The Qianmutian peat humification records of Mt. Tianmu in northwest Zhejiang and records from the muddy area on the inner shelf of the East China Sea outside the Oujiang River estuary reveal the process of Holocene climate change in Zhejiang region (Ma et al., 2009; Liu et al., 2010; Figure 6). The previous studies indicate that, between 8400-6300 cal. a BP, the East Asian winter monsoon was strong and volatile, but the temperature was higher on the whole in the region; while vegetation was mainly north subtropical forest represented by Quercus-evergreen, Castanopsis/Lithocarpus and Tsuga type (Xu et al., 2010), indicating that the environment was relatively humid as a whole in this period. During 6300-3500 cal. a BP, the summer monsoon precipitation was at a high value as a whole with a weakened winter monsoon. During the later stage of this period, the climate fluctuated greatly, among which, around 4200 cal. a BP, monsoon precipitation intensity declined rapidly, reaching the driest period around $3700 \mathrm{cal}$. a BP and then rising again rapidly (Ma et al., 2009). The environmental characteristics of this period (i.e. around the 4000 cal. a BP climate event) were of global significance (Cullen et al., 2000; Bond et al., 2001; Wu and Liu, 2004; Booth 


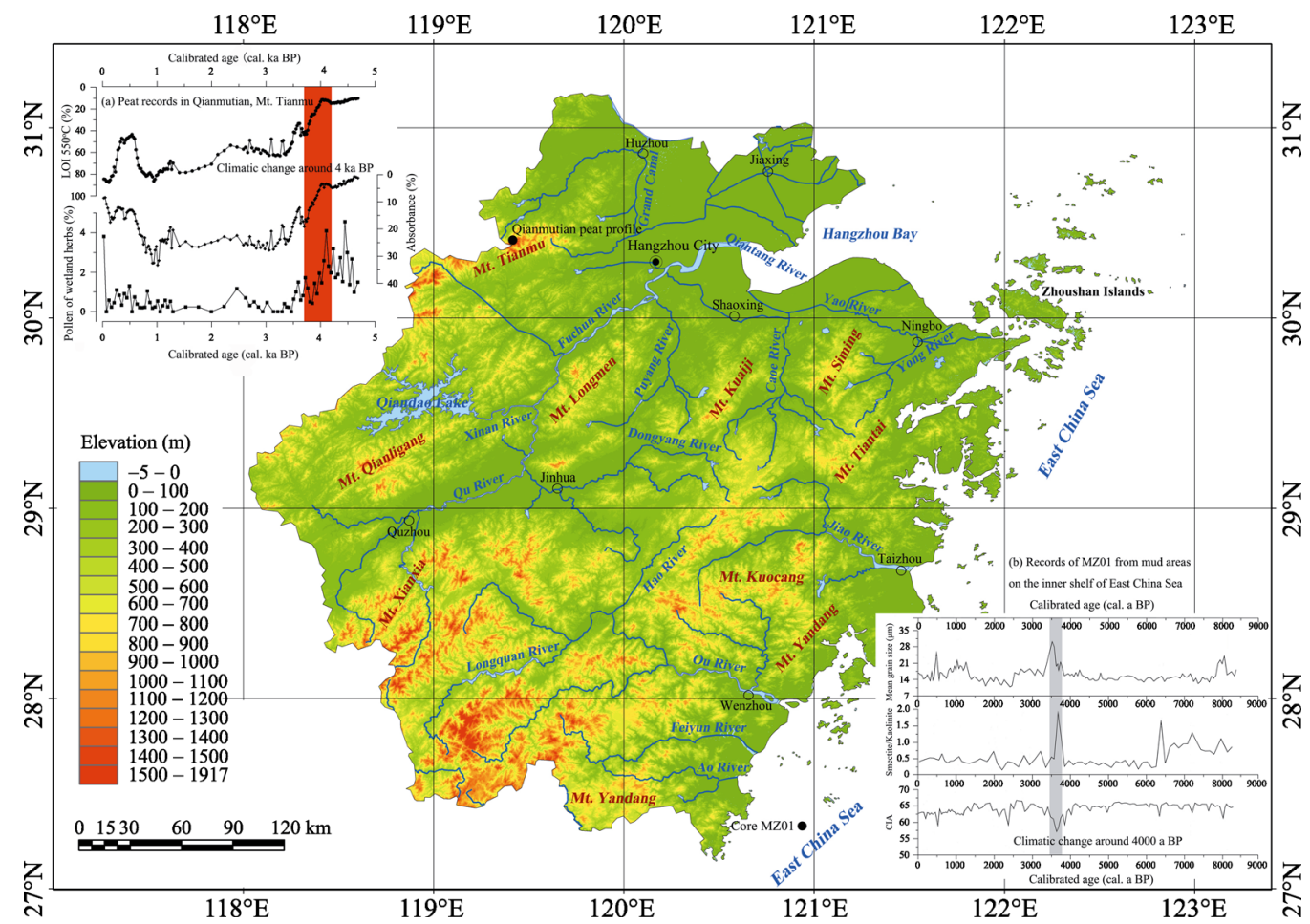

Figure 6 Environmental changes of Zhejiang around 4000 cal. a BP recorded by the Qianmutian subalpine peat in Mt. Tianmu (a) and the muddy area on the inner shelf of the East China Sea (b)

et al., 2005; Shao et al., 2006; Huang et al., 2011; Wu et al., 2012a). After 3500 cal. a BP, summer monsoon precipitation intensity was weak in the mass, but the winter monsoon was fluctuating and strengthened continuously from 1400 cal. a BP. There were also several small-scale dry-wet fluctuations in this period, and the climate environment generally presented a tendency of becoming colder and dryer.

In comparing the climate changes and prehistoric cultural changes in Zhejiang region (Table 1), we found that the time phase was consistent between prehistoric cultural changes and climate changes. During 8400-6300 cal. a BP, when the climate gradually developed from relatively cool and wet to warm and humid, it experienced the rise of Kuahuqiao Culture, Majiabang Culture and Hemudu Culture were successively. This might be related to the gradual coming of the climatic optimum warming period. The climate warm period between $6300-4200$ cal. a BP was roughly corresponding to the active era from the Songze Culture to the Liangzhu Culture. Meanwhile, there were numerous cultural sites appearing in vast areas of Zhejiang region, showing the thriving development of prehistoric cultures. This might be related to the regression process during this period. The occurrence time of the climate transitional period between 4200-3700 cal. a BP was just in conformity with the disappearance of Liangzhu Culture and the rise of Maqiao Culture. During this period, the number of cultural sites was greatly reduced, with the phenomenon of living space contraction, cultural property change and cultural recession. These all might be related to the $4000 \mathrm{cal}$. a BP abrupt change of climate (Cullen et al., 2000; Bond et al., 2001; Wu and Liu, 2004; Booth et 
al., 2005; Shao et al., 2006; Huang et al., 2011; Wu et al., 2012a). These phenomena indicate that there were internal relationships between the prehistoric cultural vicissitude and climate changes.

Table 1 Prehistoric cultures of Zhejiang region and the number of archaeological sites

\begin{tabular}{|c|c|c|c|c|}
\hline Cultural period & Cultural category & Number of sites & Proportion $(\%)$ & Total number of sites \\
\hline \multirow{2}{*}{ Shangshan-Xiaohuangshan } & Shangshan & 1 & 50 & \multirow{2}{*}{2} \\
\hline & Xiaohuangshan & 1 & 50 & \\
\hline Kuahuqiao & Kuahuqiao & 1 & 100 & 1 \\
\hline \multirow{2}{*}{ Majiabang-Hemudu } & Majiabang & 41 & 55.4 & \multirow{2}{*}{74} \\
\hline & Hemudu & 33 & 44.6 & \\
\hline \multirow{2}{*}{ Songze-Hemudu } & Songze & 28 & 45.9 & \multirow{2}{*}{61} \\
\hline & Hemudu & 33 & 54.1 & \\
\hline \multirow{2}{*}{ Liangzhu } & Liangzhu & 275 & 58.4 & \multirow{2}{*}{471} \\
\hline & Others & 196 & 41.6 & \\
\hline \multirow{2}{*}{ Maqiao } & Maqiao & 34 & 37.8 & \multirow{2}{*}{90} \\
\hline & Others & 56 & 62.2 & \\
\hline
\end{tabular}

\subsection{Impact of climate change on the prehistoric culture}

\subsubsection{Impact of climate on production activities of prehistoric culture in Zhejiang}

From archaeological data, the prehistoric cultural vicissitude of Zhejiang region was accompanied by a certain change of production activities (Jiao, 2010). Represented by some early Neolithic cultures, in particular the Shangshan Culture and the Xiaohuangshan Culture, rice cultivation had become a part of economic activity, and there were long-term settled villages with more mature technology, such as ceramics (Wang, 2006; Jiang and Sheng, 2007). The Kuahuqiao Culture also took rice cultivation, terrestrial plant collection and animal hunting as the main forms of livelihood (Yang and Jiang, 2010), but residents had come to know and use the sea at that time. The Kuahuqiao site unearthed the earliest canoes, indicating that Kuahuqiao people had begun to use boats (Zong et al., 2007). However, this period was just the initial stage of the marine economy. Marine animal remains unearthed from the site include dolphin, and sea turtle, etc. in small amount (ZPICRA, 2004), which indicate that the acquisition of marine animals was only the supplement of agricultural economic activities. The Hemudu cultural period entered a new marine economic development stage. Although rice cultivation, terrestrial plant collection and animal hunting were still the main economic forms during this period, the marine economy and prehistoric navigation of the coastal Zhejiang had developed to a higher level (ZPICRA, 2003). The existing archaeological materials indicate that, at least six kinds of marine animals had become regular fishing catches of Hemudu Cultural ancients, including sea turtle, whale, shark, naked top snapper, tuna and sea crab. Seashells could also be the important food source of Hemudu ancestors. More than $20 \%$ of the unearthed potteries are decorated with the shell plating at the Hemudu site. The Tianluoshan site of Hemudu Culture also found some potteries with 
shells. There were a number of wood pulps found in the Hemudu and Tianluoshan sites, showing that the Hemudu ancestors had been very good with boat technology (Li et al., 2010). Therefore, in the late stage of Hemudu Culture, the cultural and economic forms of Zhejiang region were changing; compared with rice agriculture, marine resources became a more important source of food. After the Hemudu Culture, the regional differentiation of Neolithic cultures emerged in the coastal area of Zhejiang, mainly reflected in the differentiation of economic forms. During the Liangzhu cultural period, inland residents still gave priority to a rice based agrarian economy, while coastal residents attached equal importance to the marine economy and the agricultural economy. Meanwhile, island residents (such as residents in the Zhoushan Islands and Nanji Islands) basically gave priority to the marine economy, and did not engage in any agricultural activity. The navigation technology of these island residents developed to a higher level, and they could often come-and-go across the islands or between island and land (Tsang, 2001; Jiao, 2007). During this period, ancestors' further adaptation and development of the ocean pushed the marine economy and marine culture into a peak stage of Zhejiang's prehistoric era. However, great changes took place in the economic forms during the Maqiao cultural period. In the north of Zhejiang, the proportion of rice cultivated agriculture in Maqiao Culture's economic life was noticeably less than the Liangzhu Culture (SMCPAM, 2002). According to the minimum individual statistics of unearthed animal remains of Maqiao Culture, the number of pigs was more than cervid animals during the Liangzhu cultural period, but the number of pigs was less than cervid animals during the Maqiao cultural period, especially in the early Maqiao Culture. This indicates that, from the Liangzhu Culture to the Maqiao Culture (Table 2), ancient people's meat resources changed from the animal husbandry as the main form with hunting as complement to the hunting as the main form with animal husbandry as complement. In the south of Zhejiang, for example, the Huangguashan Culture was distributed mainly in the coastal area of the Oujiang River estuary, although agricultural production and marine fishing still coexisted, the agricultural economy became more important, and marine economy was no longer in a leading position. The remains of rice phytolith and grain were widespread in the site formations of Huangguashan Culture, and new crops such as barley and wheat were also found in later formations (Jiao, 2010). In the animal bones unearthed from the Huangguashan cultural sites, pigs' remains number over $25 \%$, suggesting that livestock farming also became an important source of food (Jiao, 2007).

It can be seen from the above discussion that obvious changes took place in economic forms of prehistoric cultures in Zhejiang region around 4000 cal. a BP. The economic form mainly changed twice: the first occurred in the late stage of the Hemudu Culture, the second

Table 2 Minimum individual proportions (\%) of pig and cervid animals excavated from Liangzhu and Maqiao cultures

\begin{tabular}{ccccc}
\hline \multirow{2}{*}{ Cultural period } & \multicolumn{4}{c}{ Animal names } \\
\cline { 2 - 5 } & Pig & Elaphursu davidianus & Cervus nippon & Small cervid animals \\
\hline Liangzhu Culture & 50 & 6.25 & 25 & 12.5 \\
Early Maqiao Culture & 15.78 & 14 & 33.3 & 29.8 \\
Late Maqiao Culture & 27.5 & 8.4 & 32.6 & 25 \\
\hline
\end{tabular}

Data source: Shanghai Municipal Commission for the Preservation of Ancient Monuments, 2002. Maqiao: Report on Excavation between 1993 and 1997. Shanghai: Shanghai Fine Arts Publisher. 
was in the transition period from the Liangzhu Culture to the Maqiao Culture around 4000 cal. a BP. The root cause for this kind of economic change in production should be climate change. In the Holocene climatic optimum, the economy of original inhabitants was mainly focused around agricultural planting. This is also the important reason that these cultural forms spread along the river valleys to the eastern part with flat terrain and better hydrothermal conditions. Favourable climate and flat-fertile land are suitable for developing agriculture. In the meantime, since the study area has experienced a low sea-level phase between 7000-4000 cal. a BP (Zhu et al., 2003; Wu et al., 2012a), the sea-level dropped and the land area increased. The coastal lowland of Zhejiang was exposed, and the marine environment was open and stable, which provided good conditions for the development of marine economy and culture in this area. This kind of production pattern led to the geographical distribution pattern of island residents. However, the climate became dryer and colder around 4200 cal. a BP, and the change has reached its apex around $4000 \mathrm{cal}$. a BP. Meanwhile, the adjustment of East Asian climate system appeared, and the summer monsoon intensity declined rapidly, with the increased climate changing rate and frequent disasters. This is the widely proved "Holocene Event 3" (Wu and Liu, 2004). This climatic event led to the difference of production activity changes in different parts of Zhejiang region. In the north of Zhejiang, the main economic activities of the Liangzhu Culture were based on rice cultivated agriculture, which required higher conditions of sunlight and rainfall. The cold and drought caused by this climatic event had extremely adverse effects on rice growing. With the deterioration of the living environment, the vulnerability of Liangzhu Culture response to environmental disaster events and social crisis was greatly increased. Instead of the Liangzhu Culture, in order to adapt to climate change, especially the cool weather and possible frequent flooding events (SMCPAM, 2002; Wu and Liu, 2004), the production mode of Maqiao Culture experienced a significant change; hunting became an important production activity again. In the coastal area and southern Zhejiang, due to the impact factors of lower latitude, coastal location and terrain block, the cooling and drought of this area were less severe than the northern part of Zhejiang. Thus, the agricultural economy continued to develop. However, more and more sedimentary records of marine environment pointed out that great changes have taken place in ENSO (El Niño-Southern Oscillation) around 4000 cal. a BP during the Holocene (Clement et al., 2000; Cole, 2001; Barron and Anderson, 2011; MacDonald, 2011). The coral records of Galapagos Islands and New Guinea indicate that the El Niño event was very weak before 4000 cal. a BP, and ENSO only had regular but very weak seasonal cycles; but after 4000 cal. a BP, the El Niño event was significantly stronger, and the obvious interannual variability of ENSO masked the weak seasonal changes (Tudhope et al., 2001; Riedinger et al., 2002). The interannual oscillation of El Niño and La Niña made the emergence of frequent alternation between typhoon-storm surges, monsoon weakening-droughts and other disasters in the west Pacific region (Sandweiss et al., 1996; Xia, 1997; Rodbell et al., 1999). It was not until 3000 cal. a BP that this oscillation enhanced to the current level and tended to be stable (Riedinger et al., 2002). This was undoubtedly a huge blow to marine economic development of southeast coastal residents in the Maqiao cultural period. It was quite clear that, in the prehistoric coastal economic activities during this period, the significant increase in the proportion of agriculture and livestock, and the decline of marine economy, were the result of the ancient peoples' adaptation to the deterioration of the coastal marine environment. The agricultural economy revived again and be- 
came the important production activity. The adjustment of the above production mode means there were major changes in the activity areas of prehistoric cultures.

\subsubsection{Impact of climate on the activity areas of prehistoric culture in Zhejiang}

The previous discussion shows that the climate optimum of Zhejiang region was between 8400-4200 cal. a BP. During this period, the Majiabang Culture, which originated from the Taihu Lake Basin, settled in northern Zhejiang, and expanded rapidly, forming the Majiabang-Songze-Liangzhu cultural system. The climate was generally warm and wet with little fluctuation during this period. Therefore, the agricultural based Majiabang Culture and Songze Culture gradually expanded to the eastern coastal areas, and then occupied the vast Hangjiahu Plain. Meanwhile, the Hemudu Culture of indigenous origin in southern Zhejiang developed in the Ningshao Plain, and gradually diffused to the southeast coastal area. In addition to rice farming, terrestrial plant gathering and animal hunting, marine economic modes and prehistoric navigation developed to a higher level. During the Liangzhu cultural period, prehistoric cultures in Zhejiang reached their apex. The settlement sites not only extended all over the mountains, valleys and plains, but also were widely distributed in the lower coastal areas and offshore islands. This phenomenon that the sites generally diffused to the east coast were associated with the development demands of the northern rice agricultural economy and the southern marine economy, which responded to the relatively stable climatic environment during this period. However, after the 4000 cal. a BP abrupt climatic event, the number of settlement sites declined sharply in Zhejiang region, and the activity areas of prehistoric cultures shrunk dramatically. Especially, the number of sites reduced substantially along the broad coastal zone, and all the sites in offshore islands disappeared at the same time. This showed that prehistoric residents changed their production mode in the Maqiao cultural period. In northern Zhejiang, the main economic form of Maqiao Culture turned to hunting and gathering activities again, with atrophy of rice agriculture. But in the southern Zhejiang, due to the marine economic decline of each prehistoric culture, the agricultural economy became the more important production activity again. The common result brought by two different modes of production and economic transitions of the north and south Zhejiang region, was the termination of the eastward expansion of prehistoric cultures to the coastal zone sustaining more than 7000 years in Zhejiang region.

Thus it can be seen that these two significant expansions (i.e. the Majiabang-Hemudu cultural period and the Liangzhu cultural period) and a significant contraction (i.e. the Maqiao cultural period) of prehistoric cultures were positively correlated with the climate environment in Zhejiang region. This has much in common with many modern theories about the influence of climate environment on the early human civilization (Cullen et al., 2000; Polyak and Asmerom, 2001; Núñez et al., 2002; Haug et al., 2003; Yasuda et al., 2004; Booth et al., 2005; Turney and Brown, 2007; Chen et al., 2008; Liu et al., 2010; Wu et al., 2010, 2012b; MacDonald, 2011).

According to the above discussion, it can be found that the climate change triggered changes of production-life styles and economic forms, and these induced prehistoric inhabitants to change their area of activity, even brought on the rise of a new cultural form. Therefore, climate change was the important inducement of the prehistoric cultural change in Zhejiang region, which showed great influence on the distribution, diffusion, expansion and evolution of the prehistoric cultures. 


\section{Conclusions}

(1) The prehistoric cultures in Zhejiang region were disseminated from west to east coast along the river valleys with east-west or northeast-southwest directions in space. The notable territory expansions occurred twice, one in the Majiabang-Hemudu cultural period, the other in the Liangzhu cultural period. Meanwhile, the cultural concentration area was moving eastward continually. However, during the Maqiao cultural period, the distributed area of each prehistoric culture contracted severely, and the spreading trend to the east coast by settlement sites terminated.

(2) The distribution of prehistoric cultures was closely related with the sea-level fluctuations since the Holocene, especially on the banks of Hangzhou Bay, where the distribution of prehistoric cultural sites was greatly affected by sea-level changes, with the closest relationships between them. After 7000 cal. a BP, the process of lowered sea-level and regression-epeirogeny provided wider terrestrial living spaces for prehistoric inhabitants.

(3) There were significant correlations of climate change, distribution and vicissitude of prehistoric cultures in Zhejiang region. During the climatic optimum of 8400-4200 cal. a BP, the main production activity of the Majiabang-Songze-Liangzhu cultural system was rice farming. This cultural system was mainly distributed over the Hangjiahu Plain as the core zone, and had not crossed the Mt. Tianmu on the west side, but spread eastwards to the coastal lowland. The main production activities were also rice farming, gathering and hunting. However, the marine economy and navigation developed rapidly. This cultural system was mainly distributed over the Ningshao Plain, and had not crossed the Qiantang River on the west side, but diffused to the southeast coast and islands along the coastline on the east side. During the Liangzhu cultural period, the differentiation of marine economy and agricultural economy formed and coexisted in most areas of Zhejiang. This phenomenon that the sites generally diffused to the east coast was associated with the development demands of the northern rice based agrarian economy and the southern marine economy, which responded to the relatively stable climatic environment and the process of lowered sea-level and regression-epeirogenesis during this period. After the climatic transitional period between 4200-4000 cal. a BP, the Maqiao Culture replaced the Liangzhu Culture, and production activities again featured more factors of hunting and gathering, which responded to the development of a colder and dryer climatic environment. But in southern Zhejiang, the prehistoric cultures featured the phenomenon of the decline of marine economy and the reviving of the agricultural economy, which responded to the deterioration of coastal marine environment. The common result brought by two different modes of production transitions was the termination of the eastward expansion of prehistoric cultures to the coastal zone sustaining more than 7000 years in Zhejiang region. The above changes of economic forms were actually the response to the major change of climatic environment around 4000 cal. a BP in this region.

(4) Before 4000 cal. a BP, the eastward expansion of prehistoric cultures in Zhejiang occurred under the background of the Holocene Optimum, and was the expansion and extension under the joint influences of agricultural civilization and maritime civilization. However, after 4000 cal. a BP, the geographical contraction of prehistoric cultures in Zhejiang occurred under the background of dry-cold climate trend and deterioration of coastal marine environment, which was also accompanied by two different modes of production and eco- 
nomic transitions of the north and south Zhejiang region respectively. Therefore, the change of the climatic environment triggered transitions of original production mode and economic form of prehistoric inhabitants. Then, new production modes and economic forms brought on the changes of new activity spheres (e.g. changes of location for settlements), thus leading to the rise of new cultures. In conclusion, the climatic environment is the dominant impact factor of prehistoric culture vicissitudes in Zhejiang region, which has exerted great influence on distribution, dissemination, expansion and transmutation of the culture.

\section{Acknowledgements}

The authors express their sincere thanks to Prof. Jiayi Xiao from Nanjing Normal University and Prof. Zhuowei Tang from Jilin University for their constructive suggestions that greatly improved this manuscript, as well as the Computer Network Information Center, Chinese Academy of Sciences for providing the materials of land use data and DEM.

\section{References}

Barron J A, Anderson L, 2011. Enhanced Late Holocene ENSO/PDO expression along the margins of the eastern North Pacific. Quaternary International, 235: 3-12.

Bond G, Kromer B, Beer J et al., 2001. Persistent solar influence on North Atlantic climate during the Holocene. Science, 294: 2130-2136.

Booth R K, Jackson S T, Forman S L et al., 2005. A severe centennial-scale drought in mid-continental North America 4200 years ago and apparent global linkages. The Holocene, 15(3): 321-328.

Cai B Q, 2001. Culture and environment across the Hangzhou Bay in the Neolithic Age. Journal of Xiamen University (Arts \& Social Sciences), (3): 126-133. (in Chinese)

Chen Z Y, Zong Y Q, Wang Z H et al., 2008. Migration patterns of Neolithic settlements on the abandoned Yellow and Yangtze River deltas of China. Quaternary Research, 70: 301-314.

Clement A C, Seager R, Cane M A, 2000. Suppression of El Niño during the mid-Holocene by changes in the Earth's orbit. Paleoceanography, 15(6): 731-737.

Cole J, 2001. A slow dance for El Niño. Science, 291: 1496-1497.

Cullen H M, deMenocal P B, Hemming S et al., 2000. Climate change and the collapse of the Akkadian empire: Evidence from the deep sea. Geology, 28(4): 379-382.

Fang X Q, Ge Q S, Zheng J Y, 2004. Progress and prospect of researches on impacts of environmental changes on Chinese civilization. Journal of Palaeogeography, 6(1): 85-94. (in Chinese)

Feng H Z, Wang Z T, 1986. Zhejiang's Holocene coastline shift and sea level change. Journal of Hangzhou University, 13(1): 100-107. (in Chinese)

Gu M G, Chen Z D, Wang Q H et al., 2005. Geochemical records of Holocene sediments in the Xianghu section, Hangzhou, and their geological significance. Geology in China, 32(1): 70-74. (in Chinese)

Haug G H, Günther D, Peterson L C et al., 2003. Climate and the collapse of Maya civilization. Science, 299: 1731-1735.

Huang C C, Pang J L, Zha X C et al., 2011. Extraordinary floods related to the climatic event at 4200 a BP on the Qishuihe River, middle reaches of the Yellow River, China. Quaternary Science Reviews, 30: 460-468.

Innes J B, Zong Y, Chen Z et al., 2009. Environmental history, palaeoecology and human activity at the early Neolithic forager/cultivator site at Kuahuqiao, Hangzhou, eastern China. Quaternary Science Reviews, 28: 2277-2294.

Jiang D Y, Wang X P, Hao W C, 1999. Mid-Holocene paleoclimatic-paleoenvironmental changes in Zhejiang Province and Hemudu ancients. Acta Scientiarum Naturalium Universitatis Pekinensis, 35(2): 248-253. (in Chinese)

Jiang L P, 1999. Tashan tombs of lower strata and Tashan Culture. Southeast Culture, (6): 26-35. (in Chinese)

Jiang L P, Sheng D P, 2007. Shangshan Sites and Shangshan Culture: A discussion on Neolithic archaeological 
research in Zhejiang Province. In: Zhou Kunshu, Bao Xianlun. Researches of Environmental Archaeology (Volume 4). Beijing: Peking University Press, 25-42. (in Chinese)

Jiao T L, 2007. The Neolithic of Southeast China: Cultural Transformation and Regional Interaction on the Coast. New York: Cambria Press.

Jiao T L, 2010. Transition of the economic formation of the southeast coast of the Neolithic and the spread of Austronesian. In: Oriental Archaeology Research Center of Shandong University. Oriental Archaeology (Volume 7). Beijing: Science Press, 128-135. (in Chinese)

Li M L, Mo D W, Mao L J et al., 2010. Paleosalinity in the Tianluoshan site and the correlation between the Hemudu culture and its environmental background. Journal Geographical Sciences, 20(3): 441-454.

Lin G W, 2003. Fujian archaeology: Retrospect and consideration. Archaeology, (12): 7-18. (in Chinese)

Liu F G, Zhang Y L, Feng Z D et al., 2010. The impacts of climate change on the Neolithic cultures of Gansu-Qinghai region during the late Holocene Megathermal. Journal of Geographical Science, 20(3): 417-430.

Liu J W, Zhao S J, Cheng J et al., 2007. A study of vegetation and climate evolution since the Holocene near the banks of the Qiantang River in Hangzhou Bay. Earth Science Frontiers, 14(5): 235-245. (in Chinese)

Liu S F, Shi X F, Liu Y G et al., 2010. Records of the East Asian winter monsoon from the mud area on the inner shelf of the East China Sea since the mid-Holocene. Chinese Science Bulletin, 55(21): 2306-2314.

Ma C M, Zhu C, Zheng C G et al., 2009. Climate changes in East China since the late-glacial inferred from high-resolution mountain peat humification records. Science in China Series D: Earth Sciences, 52(1): $118-131$.

MacDonald G, 2011. Potential influence of the Pacific Ocean on the Indian summer monsoon and Harappan decline. Quaternary International, 229: 140-148.

Mao L J, Mo D W, Jiang L P et al., 2008. Environmental change since mid-Pleistocene recorded in Shangshan archaeological site of Zhejiang. Journal of Geographical Sciences, 18(2): 247-256.

Mo D W, Zhao Z J, Xu J J et al., 2010. Holocene environmental changes and the evolution of the Neolithic cultures in China. In: Martini I P, Chesworth W eds. Landscapes and Societies. Dordrecht, Heidelberg, London, New York: Springer Science+Business Media B.V., 299-319.

Núñez L, Grosjean M, Cartajena I, 2002. Human occupations and climate change in the Puna de Atacama, Chile. Science, 298: 821-824.

Polyak V J, Asmerom Y, 2001. Late Holocene climate and cultural changes in the southwestern United States. Science, 294: 148-151.

Riedinger M A, Steinitz-Kannan M, Last W M et al., 2002. A $\sim 6100{ }^{14} \mathrm{C}$ yr record of El Niño activity from the Galápagos Islands. Journal of Paleolimnology, 27: 1-7.

Rodbell D T, Seltzer G O, Anderson D M et al., 1999. An 15,000-year record of El Niño-driven alleviation in southwestern Ecuador. Science, 283: 516-520.

Sandweiss D H, Richardson III J B, Reitz E J et al., 1996. Geoarchaeological evidence from Peru for a 5000 years B.P. onset of El Niño. Science, 273: 1531-1533.

Shanghai Municipal Commission for the Preservation of Ancient Monuments (SMCPAM), 2002. Maqiao: Report on Excavation between 1993 and 1997. Shanghai: Shanghai Fine Arts Publisher. (in Chinese)

Shao X H, Wang Y J, Cheng H et al., 2006. Long-term trend and abrupt events of the Holocene Asian monsoon inferred from a stalagmite $\delta^{18} \mathrm{O}$ record from Shennongjia in Central China. Chinese Science Bulletin, 51(2): 221-228.

Shi C X, Mo D W, Li C H et al., 2011. The relationship between environmental evolution and human activities in Liangzhu sites group, Zhejiang Province, China. Earth Science Frontiers, 18(3): 347-356. (in Chinese)

Shi W, Ma C M, Jiao F et al., 2008. Archaeological sites, buried peat and fluctuation of sea-level in Holocene in the Ningshao Plain in Zhejiang Province, China. Acta Oceanologica Sinica, 30(4): 169-175. (in Chinese)

Shu J H, 2010. The designs of Haochuan Culture potteries. China Ceramics, 2010, 46(6): 78-81, 93. (in Chinese)

Shu J W, Wang W M, Jiang L P et al., 2010. Early Neolithic vegetation history, fire regime and human activity at Kuahuqiao, Lower Yangtze River, East China: New and improved insight. Quaternary International, 227: $10-21$.

Song J, 1999. The regions and modes of Maqiao Culture. Southeast Culture, (6): 6-14. (in Chinese)

State Administration of Cultural Heritage (SACH), 2009. An Atlas of Chinese Cultural Relics in Zhejiang Prov- 
ince. Beijing: Cultural Relics Press. (in Chinese)

Sun G P, 2002. A discussion on the geographical environment features of prehistoric sites in Ningbo-Shaoxing Area and the relevant problems. Southeast Culture, (3): 16-23. (in Chinese)

Tsang C H, 2001. Maritime adaptations in prehistoric southeast China: Implications for the problem of Austronesian expansion. Journal of East Asian Archaeology, 3(1/2): 15-46.

Tudhope A W, Chilcott C P, McCulloch M T et al., 2001. Variability in the El Niño-Southern Oscillation through a glacial-interglacial cycle. Science, 291: 1511-1517.

Turney C S M, Brown H, 2007. Catastrophic early Holocene sea level rise, human migration and the Neolithic transition in Europe. Quaternary Science Reviews, 26: 2036-2041.

Wang X X, 2006. Xiaohuangshan Hill: An archaeological examination. Journal of Shaoxing University, 26(2): 6-10, 20. (in Chinese)

Wu L, Li F, Zhu C et al., 2012a. Holocene environmental change and archaeology, Yangtze River Valley, China: Review and prospects. Geoscience Frontiers, 3(6): 875-892.

Wu L, Wang X Y, Zhou K S et al., 2010. Transmutation of ancient settlements and environmental changes between 6000-2000 aBP in the Chaohu Lake Basin, East China. Journal of Geographical Sciences, 20(5): $687-700$.

Wu L, Wang X Y, Zhu C et al., 2012b. Ancient culture decline after the Han Dynasty in the Chaohu Lake basin, East China: A geoarchaeological perspective. Quaternary International, 275: 23-29.

Wu L, Zhu C, Zheng C G et al., 2014. Holocene environmental change and its impacts on human settlement in the Shanghai area, East China. Catena, 114: 78-89.

Wu W T, 1983. Holocene palaeogeography along the Hangzhou Bay as constructed on the basis of Neolithic cultural remains. Acta Geographica Sinica, 38(2): 113-127. (in Chinese)

Wu W X, Liu T S, 2004. Possible role of the "Holocene Event 3" on the collapse of Neolithic Cultures around the Central Plain of China. Quaternary International, 117: 153-166.

Xia Z K, 1997. Quaternary Environment. Beijing: Peking University Press. (in Chinese)

Xu D K, Lu H Y, Wu N Q et al., 2010. 30 000-year vegetation and climate change around the East China Sea shelf inferred from a high-resolution pollen record. Quaternary International, 227: 53-60.

Yan Q S, Hong X Q, 1987. Holocene transgression in the south plain of the Yangtze Delta. Acta Oceanologica Sinica, 9(6): 744-752. (in Chinese)

Yan Q S, Huang S, 1987. Evolution of Holocene sedimentary environment in the Hangzhou-Jiaxing-Huzhou Plain. Acta Geographica Sinica, 42(1): 1-15. (in Chinese)

Yan Q S, Shao X S, 1989. Evolution of shorelines along the north bank of Hangzhou Bay during the late stage of the Holocene transgration. Science China Chemistry, 32: 347-360.

Yang X Y, Jiang L P, 2010. Starch grain analysis reveals ancient diet at Kuahuqiao site, Zhejiang Province. Chinese Science Bulletin, 55(12): 1150-1156.

Yasuda Y, Fujiki T, Nasu H et al., 2004. Environmental archaeology at the Chengtoushan site, Hunan Province, China, and implications for environmental change and the rise and fall of the Yangtze River civilization. Quaternary International, 123-125: 149-158.

Ye W, Li L X, Zhu L D et al., 2010. Analysis of Holocene civilization response to the paleo-environmental evolution in Zhejiang Province. Journal of Zhejiang Normal University (Nat. Sci.), 33(4): 459-464. (in Chinese)

Zhejiang Provincial Institute of Cultural Relics and Archaeology (ZPICRA), 2003. Hemudu: A Neolithic Site and Its Archaeological Excavations. Beijing: Cultural Relics Publishing House. (in Chinese)

Zhejiang Provincial Institute of Cultural Relics and Archaeology (ZPICRA), Xiaoshan Museum, 2004. Archaeological Report of Puyang River Valley I: Kua Hu Qiao. Beijing: Cultural Relics Publishing House. (in Chinese)

Zhu C, Zheng C G, Ma C M et al., 2003. On the Holocene sea-level high stand along the Yangtze Delta and Ningshao Plain, East China. Chinese Science Bulletin, 48(24): 2672-2683.

Zong Y, Chen Z, Innes J B et al., 2007. Fire and flood management of coastal swamp enabled first rice paddy cultivation in east China. Nature, 449: 459-462. 